\title{
Teoria da Contabilidade: uma Análise da Disciplina nos Programas de Mestrado Brasileiros
}

\author{
Accounting Theory: an Analysis of Discipline in the Brazilian Master Programs
}

\author{
José Alonso Borba \\ Doutor em Controladoria e Contabilidade - USP \\ Professor do Programa de Pós-graduação em Contabilidade da UFSC \\ Centro Sócio-Econômico, Departamento de Ciências Contábeis, UFSC \\ Campus Universitário - Trindade - 88040-500 - Florianópolis, SC - Brasil \\ jalonso@cse.ufsc.br \\ Fabiana Zandonai Poeta \\ Mestranda em Contabilidade - UFSC \\ Centro Sócio-Econômico, Departamento de Ciências Contábeis, UFSC \\ Campus Universitário - Trindade - 88040-500 - Florianópolis, SC - Brasil \\ fabianazandonai@hotmail.com \\ Ernesto Fernando Rodrigues Vicente \\ Doutor em Administração - USP \\ Professor do Programa de Pós-graduação em Contabilidade - UFSC \\ Centro Sócio-Econômico, Departamento de Ciências Contábeis, UFSC \\ Campus Universitário - Trindade - 88040-500 - Florianópolis, SC - Brasil \\ e.fernando@cse.ufsc.br
}

\section{Resumo}

Dada a importância de uma boa base teórica para o sucesso de profissionais e estudantes de contabilidade, o presente trabalho visa verificar junto aos programas de mestrado em contabilidade do Brasil, as ementas e bibliografias da disciplina Teoria da Contabilidade, de modo a relacionar o conteúdo proposto nas ementas e a bibliografia sugerida, com livros de relevância sobre o tema. Busca-se, ainda, comparar a oferta da disciplina nos programas de mestrado brasileiros com alguns dos melhores programas de mestrado americanos. Utilizou-se como base para a realização da pesquisa as obras de Hendriksen e Van Breda e de Iudícibus. Além das obras base, foram utilizados mais sete livros, entre obras nacionais e estrangeiras, sobre teoria da contabilidade, para compor a análise. Em seguida, os temas tratados por esses autores foram agrupados em 11 tópicos por afinidade de assuntos. Verificou-se, entre outros aspectos, uma freqüência relativamente alta em todos os tópicos temáticos, com destaque para os Postulados, Princípios e Convenções, enquanto que temas como Contabilidade e as Flutuações de Preços e Regulamentação Contábil obtiveram os menores índices. Na análise quanto à abordagem das ementas, verifica-se que dentre os 15 programas de mestrado, 10 possuem uma frequiência entre 63,6 e $72,7 \%$ do total de 11 tópicos. É possível concluir que parece existir uma lógica no ensino da Teoria da Contabilidade pelos programas de mestrado, pois foi possível constatar que os temas abordados pelas obras base tendem a refletir os temas também abordados por diversos outros autores de teoria da contabilidade. Nos programas americanos, verificou-se escassa oferta da disciplina, sendo que apenas três oferecem disciplinas mais específicas relativas à teoria da contabilidade.

Palavras-chave: Teoria da Contabilidade. Mestrado em Contabilidade. Ementas.

Artigo submetido em 21 de julho de 2011 e aceito em 31 de outubro de 2011 pelo Editor Marcelo Alvaro da Silva Macedo, após double blind review. 


\begin{abstract}
Given the importance of a good theoretical basis for the success of accounting professionals and students, this paper aims to analyze master of accounting programs in Brazil, focusing in the syllabus and bibliographies of the discipline Accounting Theory, and relating it with relevant books about the discipline. Also, we compare the discipline (Accounting Theory) in Brazilian master of accounting programs with its correspondent in master of accounting programs in the United States. We used, as the relevant books, the text-books of Hendriksen and Van Breda and Iudícibus. In addition to the main text-books, we used another seven textbooks, including national and foreign works on accounting theory, to make the analysis. The subjects covered by these authors were grouped into 11 topics by affinity issues. Results show, among other things, a relatively high frequency of all topics in Brazilian master of accounting programs, especially Postulates, Principles and Conventions, while topics such as Accounting and Price Fluctuations and Accounting Regulation had lower rates. Analyzing the syllabus, we find that among the 15 Brazilian master of accounting programs, 10 have a frequency between 63.6 and $72.7 \%$ of the 11 topics. It is possible to conclude that it appears to exist a logic in the teaching of accounting for Brazilian master of accounting programs, for it was established that the basic issues addressed by the main books tend to reflect the issues also addressed by several other authors of accounting theory. The U.S. master of accounting program showed a low presence of Accounting Theory discipline, as only three offers of subjects relating to accounting theory were found.
\end{abstract}

Keywords: Accounting Theory. Master in Accounting. Course Menu.

\title{
1. Introdução
}

A contabilidade está em um momento de rápida transição, seu ambiente passou por grandes mudanças nas últimas duas décadas, e um ritmo acelerado de mudanças ainda está na perspectiva para o futuro (GLAUTIER e UNDERDOWN, 1995). Diante destas mudanças, torna-se importante a compreensão da contabilidade como conhecimento, o que pode ocorrer através do estudo da Teoria da Contabilidade.

Obrigatória nos cursos de graduação em Ciências Contábeis a partir da Resolução no . 03 do Conselho Federal de Educação, de 05/10/1992, a disciplina Teoria da Contabilidade visa, conforme esta resolução, estimular a aquisição integrada de conhecimentos teóricos e práticos que permitam ao graduado o competente exercício da sua profissão.

Diante disto, o ensino e principalmente a discussão sobre teoria da contabilidade em programas de mestrado também ganha importância, tendo em vista que os mestrandos já possuem um conhecimento básico a respeito da disciplina e podem discutir sobre temas mais complexos. Sendo assim, tanto para o exercício da profissão quanto no exercício do magistério, será necessário que haja uma base teórica fundamentada, pois a partir dela podem desenvolver-se com qualidade.

Neste sentido, para Inanga e Schneider (2005, p. 233) "na ausência de teorias fundamentais de contabilidade, contadores são incapazes de avaliar efetivamente o que estão fazendo e oferecer inovação em resposta às novas demandas que possam surgir".

Com a adesão brasileira às normas internacionais de contabilidade, o que gerou um aumento na subjetividade e a ênfase nas características qualitativas da informação contábil, torna-se necessário que os profissionais tenham uma boa base teórica para que possam resolver problemas inéditos e complexos, que não estejam previstos em normas, o que de 
certo modo eleva também a responsabilidade e o reconhecimento da profissão perante a sociedade.

No ensino da Teoria da Contabilidade destaca-se, ainda, a importância do uso de obras - livros-textos, que disponibilizem visões diferentes sobre assuntos semelhantes e orientem o aprendizado. Diante disto, surge a seguinte questão-problema para o estudo: de que forma as ementas das disciplinas de Teoria da Contabilidade, ministradas nos programas de mestrado em contabilidade brasileiros, têm se relacionado com os diversos livros-texto sobre o tema?

Assim, o trabalho tem como objetivo verificar o conteúdo das ementas e bibliografias da disciplina Teoria da Contabilidade ministrada nos programas de mestrado em contabilidade do Brasil, de modo a relacionar o conteúdo proposto nas ementas e a bibliografia sugerida, com livros de relevância sobre o tema.

Objetiva-se, ainda, fazer um comparativo com os melhores programas de pósgraduação da área dos Estados Unidos, de modo a observar o oferecimento da disciplina teoria da contabilidade e verificar se há semelhanças com os programas de mestrado brasileiros.

O presente trabalho está estruturado em cinco seções, incluindo a Introdução. A Seção 2 apresenta uma breve contextualização sobre o desenvolvimento e a importância da teoria da contabilidade, e, ainda, pesquisas anteriores relacionadas com o presente artigo. Na sequiência, a Seção 3 apresenta a metodologia utilizada na pesquisa. A Seção 4 demonstra os resultados, e, finalmente a Seção 5 dispõe sobre as considerações finais do artigo.

\section{Desenvolvimento e Importância da Teoria da Contabilidade}

A contabilidade desenvolveu-se, inicialmente, de forma preponderantemente prática, com ênfase apenas nas partidas dobradas e livros de escrituração. Sá (2002) destaca que a contabilidade por muito tempo teve como significado a escrita, manutenção de livros de escrituração de "contas", apresentação de saldos de contas e dados sobre acontecimentos havidos nos negócios.

Iudícibus, Martins e Carvalho (2005, p. 9) explicam que a contabilidade, antes de ciência, foi, em seus inícios, um sistema completo de escrituração, onde sistema de escrituração e método das partidas dobradas eram sinônimos de contabilidade. Esta visão se reformulou ao longo da história, tendo a contabilidade recebido diversos outros sentidos e significados.

Com a evolução na utilização da contabilidade, esta passou a preocupar-se, de maneira mais abrangente, com os eventos econômicos relativos às entidades, de forma a traduzir aos seus interessados/usuários o que se passa em termos econômicos e financeiros em seus negócios.

Neste sentido, Iudícibus, Martins e Carvalho (2005, p. 8) enfatizam que:

\footnotetext{
"a doutrina contábil é a face científica desse encontro fértil entre a realidade e o modelo para acolhê-la e descrevê-la. Do lento, mas maravilhoso crescimento multiforme, nascem, primeiramente, a escrituração e, mais tarde, a ciência contábil e, portanto, sua doutrina".
}

Segundo Pinheiro (1997, p. 5), "deve-se reconhecer a Teoria Contábil como um meio de, cada vez mais, aumentar a capacidade de a Contabilidade ser útil aos seus usuários".

Ainda neste sentido, Glautier e Underdown (1974, apud Francalanza, 1997, p. 119) afirmam que "as práticas contábeis são o produto do pensamento, isto é, da teoria, e não viceversa. Daí os objetivos e os conceitos de contabilidade devem sempre ter precedência sobre as práticas contábeis em qualquer regime de ensino". 
A necessidade da teoria contábil é destacada por Kam (1990, p. 45), onde afirma que precisamos da teoria para nos prover respostas, segundo Kam, se pudermos formular uma "boa" teoria, então teremos "boas práticas" se a teoria for seguida.

Marion (1997, p. 4) destaca que "sair da rotina das normas habituais leva parte dos profissionais da área a buscar socorro em diversas fontes. Será que estas novas disposições são tão complexas assim ou estaria faltando embasamento teórico para interpretá-las?". Mais adiante o autor ainda infere que "é de assustar a dificuldade que muitos profissionais têm para explicar aspectos contábeis que, com base na teoria, seriam muito simples".

Fica evidente a importância da teoria da contabilidade para os profissionais e estudantes, no sentido de que a mesma serve de base para soluções de problemas práticos, assim como, para a interpretação de novas situações que porventura venham a surgir no exercício da profissão.

\subsection{Pesquisas Anteriores}

Diversas pesquisas que envolvem o estudo do conteúdo de ementas, livros-texto, planos de ensino e demais materiais relacionados ao ensino de disciplinas ou com o intuito de explorar determinados assuntos, podem ser encontradas.

Pesquisa feita por Souza et al. (2008) analisaram o ensino sobre a contabilidade gerencial em universidades brasileiras, com o intuito de verificar se as competências essenciais para os contadores gerenciais são abordadas nas ementas dos cursos de Ciências Contábeis

Em um estudo sobre a disciplina de custos, Gallon et al. (2005) verificaram as congruências e divergências desta disciplina ofertada nos Cursos de Ciências Contábeis das universidades ligadas à Associação Catarinense das Fundações Educacionais (ACAFE), para isto, realizaram a análise de conteúdo das ementas, a carga horária e a disposição das disciplinas de custos na grade curricular.

Fernández (2010) analisou 150 livros de finanças corporativas, publicados entre 1979 e 2009, com o intuito de analisar as recomendações dos diversos autores a respeito de suas recomendações em relação à faixa de prêmio risco de mercado, de 3 a $10 \%$. Ainda em relação à análise de livros-texto, Luehlfing (1995) verificou como são abordados os métodos de consolidação de acordo com diversos livros-texto.

Raupp et al. (2009) realizaram estudo descritivo sobre o perfil do ensino de Contabilidade de Custos nos cursos de graduação em Administração do Estado de Santa Catarina, utilizando-se como base os planos de ensino e ementas de Instituições de Ensino Superior.

Através da comparação de livros de contabilidade financeira introdutória, Sullivan e Benke Jr. (1997) desenvolveram estudo para auxiliar na escolha de um livro a ser utilizado em uma faculdade de contabilidade.

Luz, Rengel e Domingues (2010) avaliaram as semelhanças e as discrepâncias existentes na indicação de obras didáticas constantes nos Projetos Pedagógicos de cursos de graduação em Ciências Contábeis e as comparou com aquelas sugeridas na Proposta Nacional de Conteúdo para o Curso de Graduação em Ciências Contábeis do Conselho Federal de Contabilidade.

Lopes et al. (2007) verificaram o grau de presença dos principais conceitos de contabilidade estratégica, através das ementas das disciplinas dos cursos de Graduação em Ciências Contábeis das Instituições de Ensino Superior (IES) públicas do Estado do Rio de Janeiro. 


\section{Metodologia}

Quanto ao delineamento da pesquisa, em relação aos objetivos é descritiva. Andrade (2000 apud BEUREN et al 2003, p. 81) destaca que a pesquisa descritiva preocupa-se em observar os fatos, registrá-los, analisá-los, classificá-los e interpretá-los, e o pesquisador não interfere neles.

Em relação ao procedimento, a pesquisa caracteriza-se como bibliográfica, segundo Lakatos (1992, p. 183) a pesquisa bibliográfica abrange toda a bibliografia tornada pública em relação ao tema estudado, desde publicações avulsas, boletins, jornais, revistas, livros, pesquisas, monografias, teses, material cartográfico, etc.

No que se refere à abordagem do problema, é qualitativa, Raupp e Beuren (2004, p. 93) descrevem que na pesquisa qualitativa ocorrem análises mais profundas em relação ao fenômeno estudado podendo ser uma forma adequada para conhecer a natureza de um fenômeno.

No intuito alcançar os objetivos deste trabalho, realizou-se, inicialmente, pesquisa em livros-texto sobre Teoria da Contabilidade. O Quadro 1 apresenta as obras utilizadas.

Quadro 1 - Livros-textos utilizados na pesquisa

\begin{tabular}{|l|l|}
\hline Livro 1: & HENDRIKSEN, Eldon S.; VAN BREDA, Michael F. Teoria da Contabilidade. $5^{\text {a }}$ ed., São \\
Paulo: Atlas, 2009.
\end{tabular}

Fonte: elaborado pelos autores

A escolha dos livros-texto constitui-se de uma amostra intencional, sendo utilizadas as obras às quais os autores obtiveram acesso, escolhendo-se as mais representativas sobre o tema. Em seguida, através do portal da Coordenação de Aperfeiçoamento de Pessoal em Nível Superior - CAPES, realizou-se a coleta das ementas e bibliografias das disciplinas de Teoria da Contabilidade disponibilizadas pelos programas de mestrado acadêmico em Contabilidade do Brasil, resultando em 15 programas.

Foram considerados os programas de mestrado acadêmico em contabilidade recomendados pela CAPES, ou seja, todos os programas que obtiveram nota igual ou superior a "3" na avaliação da CAPES e que, consequentemente, atendem aos requisitos básicos estabelecidos pelo Ministério da Educação por meio do Conselho Nacional de Educação.

O Quadro 2 apresenta os programas de mestrado constantes da pesquisa, sendo apresentados a sigla da instituição a que fazem parte, seguida pelo seu referido nome e finalmente a nota obtida na última avaliação trienal da CAPES em 2010. 


\begin{tabular}{|ll|c|}
\hline \multicolumn{1}{|c}{ SIGLA } & \multicolumn{1}{c}{ Quadro 2 - Programas de mestrado utilizados na pesquisa } & NOTA \\
\hline FUCAPE & Fundação Instituição Capixaba de Pesq. em Cont. Econ. E Finanças & 4 \\
\hline FURB & Universidade Regional de Blumenau & 4 \\
\hline PUC/SP & Pontifícia Universidade Católica de São Paulo & 3 \\
\hline UERJ & Universidade do Estado do Rio de Janeiro & 3 \\
\hline UFBA & Universidade Federal da Bahia & 3 \\
\hline UFMG & Universidade Federal de Minas Gerais & 4 \\
\hline UFPE & Universidade Federal de Pernambuco & 3 \\
\hline UFPR & Universidade Federal do Paraná & 3 \\
\hline UFRJ & Universidade Federal do Rio de Janeiro & 4 \\
\hline UFSC & Universidade Federal de Santa Catarina & 4 \\
\hline UNB & Universidade de Brasília & 4 \\
\hline UniFECAP & Centro Universitário Alvares Penteado & 4 \\
\hline UNISINOS & Universidade do Vale do Rio dos Sinos & 4 \\
\hline USP & Universidade de São Paulo & 6 \\
\hline USP/RP & Universidade de São Paulo/ Ribeirão Preto & 4 \\
\hline
\end{tabular}

Fonte: elaborado pelos autores

Para a parametrização dos assuntos contidos nos livros, são utilizados como base os livros de Hendriksen e Van Breda e de Iudícibus, devido ao fato de serem citados em todas as bibliografias sugeridas pelos programas de mestrado da pesquisa. Utilizam-se obras como base, para facilitar a classificação e compreensão dos temas mais abordados sobre Teoria da Contabilidade.

Em seguida, os temas abordados nos livros base são agrupados por afinidade de assunto em 11 tópicos temáticos. O objetivo desta divisão é eliminar as possíveis particularidades dos autores, o que poderia prejudicar a busca dos temas nas demais obras pesquisadas. O Quadro 3 apresenta os 11 tópicos temáticos, seguidos, de forma resumida, dos assuntos inerentes a cada um deles.

A partir desta divisão, as demais obras são analisadas, de modo a verificar quais destes temas têm sido abordados pelos demais autores.

Após a pesquisa das obras, são analisadas as ementas da disciplina de Teoria da Contabilidade ministrada nos programas de mestrado, de modo a verificar se há uma tendência na abordagem dos temas vistos nos livros-texto.

Em seguida, verifica-se com que freqüência os livros-texto utilizados na pesquisa, fazem parte da bibliografia sugerida na disciplina de Teoria da Contabilidade nos mestrados.

Para a pesquisa dos programas de pós-graduação em contabilidade americanos, utilizou-se como base o ranking estabelecido pelo website da U.S. News \& World Report, que divulga e classifica anualmente rankings de diversas áreas, como educação saúde e economia.

Quanto às classificações relacionadas com educação, a U.S. News \& World Report divulga rankings contendo as melhores escolas, universidades, programas de pós-graduação, entre outros. 
Quadro 3 - Tópicos temáticos

1. Metodologia da Contabilidade

Abordagens e enfoques diversos: ético, comportamental, estrutural, econômico, etc. Dedução e Indução. Teorias normativa, indutiva, como linguagem, como raciocínio, como decreto. Verificação de teorias.

\section{História e Evolução da Contabilidade}

Antecedentes da contabilidade. Origem, evolução, datas e eventos importantes da contabilidade. Escolas americana e européia. Surgimento da profissão. Futuro e perspectivas da contabilidade.

\section{Postulados, Princípios e Convenções}

Natureza e definição dos postulados. Postulados da entidade e continuidade. Definição dos princípios contábeis. Convenções: objetividade, materialidade, conservadorismo, consistência. Características qualitativas e essência sobre a forma. Referencial conc

\section{O Ativo e sua Mensuração}

Definições, características e mensuração. Capacidade de geração de benefícios. Custos históricos, de entrada, de saída, variável. Depreciação e manutenção. Ativos circulantes, não circulantes, intangíveis, investimentos.

\section{O Passivo e sua Mensuração}

Natureza, definições, mensuração e reconhecimento. Encerramento de passivos. Títulos híbridos. Exigibilidades contingentes.

\section{Receitas, Despesas, Ganhos e Perdas}

Natureza e definições de receitas, despesas, ganhos e perdas. Reconhecimento e mensuração. Registro das receitas nas diversas fases de produção e venda. Associação das despesas com as receitas.

\section{Patrimônio Líquido}

Definições, classificações e diversas abordagens sobre patrimônio líquido. Aumentos e reduções do capital investido. Combinações de empresas. Lucro por ação. Dividendos.

\section{Regulamentação Contábil}

Origem, prós e contras da regulamentação. Origem do FASB e seus antecessores. O papel da Securities and Exchange Comission.

\section{Evidenciação e Divulgação}

As várias formas de evidenciação.Os usuários das informações contábeis. Níveis e formas de divulgação. Métodos de divulgação. Eficiência de mercado e divulgação de informações contábeis.

\section{A Contabilidade e as Flutuações de Preços}

Natureza das variações de preços. A contabilidade e as flutuações de preços. Correções em função das variações de preços e poder aquisitivo. Contabilização a custos correntes. Correção de balanços patrimoniais e demonstrações de resultado.

\section{Tópicos Especiais}

Tomada de decisões. Impostos diferidos. Pensões. Direitos de propriedade. Demonstração da posição financeira. Perspectivas e tendências da teoria da contabilidade.

Fonte: elaborado pelos autores

Assim, realizou-se a busca pelos melhores programas de pós-graduação em contabilidade americanos. Ao todo, são classificados trinta e dois programas, porém, são apresentados gratuitamente apenas os dez primeiros, de acordo com a posição de classificação. Deste modo, foram pesquisados os dez programas apresentados. O Quadro 4 apresenta a relação das universidades ao qual fazem parte os referidos programas, em ordem de classificação. 
Quadro 4 - Dez melhores programas de mestrado conforme U.S. News

\begin{tabular}{|c|c|}
\hline Posição Ranking & Universidade \\
\hline $1 \stackrel{0}{ }$ & University of Texas - Austin \\
\hline $2^{\circ}$. & University of Pennsylvania (Wharton) \\
\hline $3^{\circ}$. & University of Chicago (Booth) \\
\hline $4^{\circ}$. & University of Illinois (Urbana-Champaign) \\
\hline 5ㅇ. & University of Michigan (Ann Arbor) \\
\hline $6^{0}$. & Stanford University \\
\hline $7^{0}$. & Brigham Young University (Marriott) \\
\hline $8^{\circ}$. & University of Southern California (Marshall) \\
\hline 9은 & New York University (Stern) \\
\hline $10^{\circ}$ & University of North Carolina (Chapel Hill) \\
\hline
\end{tabular}

A partir da listagem de universidades acima apresentada, buscou-se, nos websites de cada universidade, se as mesmas disponibilizam em seus programas de pós-graduação a disciplina Teoria da Contabilidade.

Nos casos em que se encontrou a oferta da disciplina, buscou-se observar qual o conteúdo ministrado, de modo a fazer um comparativo com o conteúdo predominante nos programas de mestrado brasileiros constantes da pesquisa.

\section{Resultados}

Inicialmente, apresenta-se a análise realizada dos livros-texto, onde se verificou a abordagem dos temas contidos nos tópicos temáticos em todas as obras, conforme apresentados na Tabela 1, onde os campos marcados com " $\mathrm{x}$ " correspondem aos temas localizados nas obras pesquisadas e os campos em cinza correspondem aos temas não tratados pelas mesmas.

Tabela 1 - Tópicos temáticos verificados nos livros-texto

\begin{tabular}{|c|c|c|c|c|c|c|c|}
\hline Tópicos & Livro 3 & Livro 4 & Livro 5 & Livro 6 & Livro 7 & Livro 8 & Livro 9 \\
\hline 1. Metodologia da Contabilidade & $\mathrm{x}$ & $\mathrm{x}$ & $\mathrm{x}$ & $\mathrm{x}$ & $\mathrm{x}$ & $\mathrm{x}$ & $\mathrm{x}$ \\
\hline 2. História e Evolução da Contabilidade & $\mathrm{X}$ & & & $\mathrm{x}$ & & $\mathrm{x}$ & \\
\hline 3. Postulados, Princípios e Convenções & $\mathrm{x}$ & $\mathrm{x}$ & $\mathrm{x}$ & $\mathrm{x}$ & $\mathrm{x}$ & $\mathrm{x}$ & \\
\hline 4. O Ativo e sua Mensuração & $\mathrm{x}$ & $\mathrm{x}$ & $\mathrm{x}$ & $\mathrm{x}$ & & & \\
\hline 5. O Passivo e sua Mensuração & $\mathrm{x}$ & $\mathrm{x}$ & $\mathrm{x}$ & & & & \\
\hline 6. Receitas, Despesas, Ganhos e Perdas & $\mathrm{x}$ & $\mathrm{x}$ & $\mathrm{x}$ & & & & \\
\hline 7. Patrimônio Líquido & $\mathrm{x}$ & & & & & & $\mathrm{x}$ \\
\hline 8. Regulamentação Contábil & & $\mathrm{x}$ & $\mathrm{x}$ & $\mathrm{x}$ & & $\mathrm{x}$ & $\mathrm{X}$ \\
\hline 9. Evidenciação e Divulgação & $\mathrm{x}$ & $\mathrm{x}$ & $\mathrm{x}$ & $\mathrm{x}$ & $\mathrm{x}$ & & $\mathrm{X}$ \\
\hline 10. A Contabilidade e as Flutuações de Preços & & & $\mathrm{x}$ & $\mathrm{x}$ & & & $\mathrm{X}$ \\
\hline 11. Tópicos Especiais & $\mathrm{x}$ & $\mathrm{x}$ & $\mathrm{x}$ & $\mathrm{x}$ & & & \\
\hline
\end{tabular}

Fonte: elaborado pelos autores

A seguir, a Tabela 2 elucida em termos percentuais e freqüência absoluta os dados vistos anteriormente na Tabela 1. 
Tabela 2 - Freqüência relativa e absoluta dos tópicos nos livros-texto

\begin{tabular}{lcc}
\hline \multicolumn{1}{c}{ Tópicos } & \multicolumn{2}{c}{ Frequência } \\
\cline { 2 - 3 } 1. Metodologia da Contabilidade & \% & Absoluta \\
2. História e Evolução da Contabilidade & $100 \%$ & 9 \\
3. Postulados, Princípios e Convenções & $55,5 \%$ & 5 \\
4. O Ativo e sua Mensuração & $88,8 \%$ & 8 \\
5. O Passivo e sua Mensuração & $66,6 \%$ & 6 \\
6. Receitas, Despesas, Ganhos e Perdas & $55,5 \%$ & 5 \\
7. Patrimônio Líquido & $55,5 \%$ & 5 \\
8. Regulamentação Contábil & $44,4 \%$ & 4 \\
9. Evidenciação e Divulgação & $77,7 \%$ & 7 \\
10. A Contabilidade e as Flutuações de Preços & $88,8 \%$ & 8 \\
11. Tópicos Especiais & $55,5 \%$ & 5 \\
\hline
\end{tabular}

Fonte: elaborado pelos autores

É possível verificar, com base nos dados acima, que o tema Metodologia da Contabilidade aparece em $100 \%$ dos livros-texto, enquanto que os temas Postulados, Princípios e Convenções, e, Evidenciação e Divulgação constam em quase $90 \%$ dos livrostexto. Por outro lado, os temas Patrimônio Líquido e Tópicos Especiais apresentam uma frequiência aproximada de $44 \%$ e $33 \%$, respectivamente, as menores dentre os temas.

De modo geral, pode-se observar que todos os tópicos são tratados com frequiência relativamente alta no conjunto de livros-texto analisados, demonstrando que as obras utilizadas como base, de certo modo, refletem o que os demais autores de Teoria da Contabilidade têm abordado em seus livros. Isto pode ser considerado um ponto positivo quanto aos programas de mestrado, visto todos sugerirem as obras base em suas bibliografias.

A seguir, tabela 3, apresenta-se a análise realizada no conteúdo previsto nas ementas da disciplina de Teoria da Contabilidade, relativas aos programas de mestrado abordados na pesquisa. Verificou-se, dentro destas ementas, a abordagem dos temas contidos nos tópicos temáticos, onde os campos marcados com " $\mathrm{x}$ " correspondem aos temas previstos nas ementas e os campos em cinza correspondem aos temas não previstos pelas mesmas.

Tabela 3 - Tópicos temáticos verificados nas ementas

\begin{tabular}{|c|c|c|c|c|c|c|c|c|c|c|c|}
\hline \multirow{2}{*}{ Programa Mestrado - Ementas } & \multicolumn{11}{|c|}{ Tópicos } \\
\hline & 1 & 2 & 3 & 4 & 5 & 6 & 7 & 8 & 9 & 10 & 11 \\
\hline FUCAPE & $\mathrm{X}$ & $\mathrm{x}$ & $\mathrm{x}$ & $\bar{x}$ & $\mathrm{x}$ & $\mathrm{x}$ & $\mathrm{x}$ & & $\mathrm{x}$ & & $\mathrm{x}$ \\
\hline FURB & $\mathrm{x}$ & $\mathrm{x}$ & $\mathrm{x}$ & & & & & $\mathrm{x}$ & $\mathrm{x}$ & & \\
\hline PUC/SP & $\mathrm{x}$ & $\mathrm{x}$ & $\mathrm{x}$ & $\mathrm{x}$ & $\mathrm{x}$ & $\mathrm{x}$ & $\mathrm{X}$ & & & & \\
\hline UERJ & $\mathrm{x}$ & & $\mathrm{x}$ & $\mathrm{x}$ & $\mathrm{x}$ & $\mathrm{x}$ & $\mathrm{x}$ & & $\mathrm{x}$ & & \\
\hline UFBA & $\mathrm{X}$ & $\mathrm{x}$ & $\mathrm{x}$ & $\mathrm{x}$ & $\mathrm{x}$ & $\mathrm{x}$ & & $\mathrm{x}$ & $\mathrm{x}$ & $\mathrm{X}$ & $\mathrm{x}$ \\
\hline UFMG & & & $\mathrm{x}$ & $\mathrm{x}$ & $\mathrm{x}$ & $\mathrm{x}$ & $\mathrm{x}$ & & $\mathrm{x}$ & & \\
\hline UFPE & $\mathrm{x}$ & $\mathrm{x}$ & $\mathrm{x}$ & $\mathrm{x}$ & $\mathrm{x}$ & $\mathrm{x}$ & & & $\mathrm{x}$ & & \\
\hline UFPR & $\mathrm{x}$ & $\mathrm{x}$ & $\mathrm{x}$ & $\mathrm{x}$ & $\mathrm{x}$ & $\mathrm{x}$ & $\mathrm{x}$ & & $\mathrm{x}$ & & \\
\hline UFRJ & $\mathrm{X}$ & & $\mathrm{x}$ & $\mathrm{x}$ & $\mathrm{x}$ & $\mathrm{x}$ & $\mathrm{x}$ & & & & $\mathrm{x}$ \\
\hline UFSC & $\mathrm{x}$ & $\mathrm{x}$ & $\mathrm{x}$ & $\mathrm{x}$ & $\mathrm{x}$ & $\mathrm{x}$ & $\mathrm{x}$ & $\mathrm{x}$ & & & \\
\hline UNB - UFPB - UFRN & & $\mathrm{x}$ & $\mathrm{x}$ & $\mathrm{x}$ & $\mathrm{x}$ & $\mathrm{x}$ & & $\mathrm{x}$ & $\mathrm{x}$ & & \\
\hline UniFECAP & $\mathrm{x}$ & $\mathrm{x}$ & $\mathrm{x}$ & $\mathrm{x}$ & $\mathrm{x}$ & $\mathrm{x}$ & $\mathrm{x}$ & & & & $\mathrm{x}$ \\
\hline UNISINOS & $\mathrm{X}$ & $\mathrm{x}$ & $\mathrm{x}$ & $\mathrm{X}$ & $\mathrm{x}$ & $\mathrm{x}$ & $\mathrm{x}$ & & & & \\
\hline USP & $\mathrm{x}$ & $\mathrm{x}$ & $\mathrm{x}$ & $\mathrm{x}$ & $\mathrm{x}$ & $\mathrm{x}$ & $\mathrm{x}$ & $\mathrm{x}$ & & & \\
\hline USP/RP & $\mathrm{x}$ & & & & & & & $\mathrm{x}$ & $\mathrm{x}$ & & \\
\hline
\end{tabular}

Fonte: elaborado pelos autores 
Devido ao fato de algumas ementas trazerem como assunto a "estrutura conceitual básica", considerou-se que este tópico inclui os seguintes temas: ativo, passivo, receitas, despesas, ganhos, perdas, patrimônio líquido e as características qualitativas da contabilidade (neste caso, considerou-se como postulados, princípios e convenções), conforme apresentado no Pronunciamento Conceitual Básico emitido pelo Comitê de Pronunciamentos Contábeis CPC. A Tabela 3 demonstra estes dados.

$\mathrm{Na}$ sequiência, a Tabela 4 elucida em termos percentuais e freqüência absoluta os dados vistos anteriormente na Tabela 3.

Tabela 4 - Freqüência relativa e absoluta dos tópicos nas ementas

\begin{tabular}{lcc}
\hline \multicolumn{1}{c}{ Tópicos } & \multicolumn{2}{c}{ Frequência } \\
\cline { 2 - 3 } & \% & Absoluta \\
\hline 1. Metodologia da Contabilidade & $86,6 \%$ & 13 \\
2. História e Evolução da Contabilidade & $73,3 \%$ & 11 \\
3. Postulados, Princípios e Convenções & $93,3 \%$ & 14 \\
4. O Ativo e sua Mensuração & $86,6 \%$ & 13 \\
5. O Passivo e sua Mensuração & $86,6 \%$ & 13 \\
6. Receitas, Despesas, Ganhos e Perdas & $86,6 \%$ & 13 \\
7. Patrimônio Líquido & $66,6 \%$ & 10 \\
8. Regulamentação Contábil & $40,0 \%$ & 6 \\
9. Evidenciação e Divulgação & $60,0 \%$ & 9 \\
10. A Contabilidade e as Flutuações de Preços & $66,6 \%$ & 1 \\
11. Tópicos Especiais & $26,6 \%$ & 4 \\
\hline
\end{tabular}

Fonte: elaborado pelos autores

$\mathrm{Na}$ análise do conteúdo das ementas destacou-se, novamente, a abordagem do tópico relacionado aos Postulados, Princípios e Convenções, com um percentual de 93,3\%. Os tópicos com menor nível de abordagem foram os relacionados à Contabilidade e as Flutuações de Preços, Tópicos Especiais e Regulamentação Contábil.

O destaque para o conteúdo relacionado aos Postulados, Princípios e Convenções ocorre, provavelmente, pela tamanha importância destes conceitos na construção da Teoria Contábil, visto serem considerados por alguns autores como elementos fundamentais e que serviram de base a esta ciência. No entanto, os temas com um grau inferior de abordagem pelas ementas, talvez venham a refletir uma ação mais conservadora por parte dos docentes ao tratar de temas que estejam em constantes mudanças e que possam, em um futuro próximo, não mais refletir a realidade para os discentes que estudaram este conteúdo, como é o caso das flutuações de preços e regulamentação contábil.

Ao analisar-se a abordagem das ementas pelos programas de mestrado, verifica-se certo padrão na quantidade de temas previstos em suas ementas, sendo que dentre os 15 programas de mestrado, 10 possuem uma freqüência entre 63,6 e 72,7\%, ou seja, adotaram nas ementas entre sete e oito itens do total de 11 tópicos. Destaque para a UFBA que ficou com o maior índice, de $90,9 \%$ e para a USP/RP com o menor índice, de $27,2 \%$.

Algumas ementas, por serem bastante sucintas e não apresentarem o conteúdo de forma detalhada, podem fazer com que alguns itens tenham sido omitidos na análise do conteúdo nelas compreendido. A Tabela 5 demonstra estes resultados. 
Tabela 5 - Freqüência de tópicos por programas

\begin{tabular}{lcc}
\hline & \multirow{2}{*}{ Tópicos } & \multicolumn{2}{c}{ Frequência } \\
\cline { 2 - 3 } & \% & Absoluta \\
\hline FUCAPE & $81,8 \%$ & 9 \\
FURB & $45,4 \%$ & 5 \\
PUC/SP & $63,6 \%$ & 7 \\
UERJ & $63,6 \%$ & 7 \\
UFBA & $90,9 \%$ & 10 \\
UFMG & $54,5 \%$ & 6 \\
UFPE & $63,6 \%$ & 7 \\
UFPR & $72,7 \%$ & 8 \\
UFRJ & $63,6 \%$ & 7 \\
UFSC & $72,7 \%$ & 8 \\
UNB - UFPB - UFRN & $72,7 \%$ & 8 \\
UniFECAP & $72,7 \%$ & 8 \\
UNISINOS & $63,6 \%$ & 7 \\
USP & $72,7 \%$ & 8 \\
USP/RP & $27,2 \%$ & 3 \\
\hline
\end{tabular}

Fonte: elaborado pelos autores

Quanto à análise das bibliografias, verificou-se a incidência dos livros-texto utilizados nesta pesquisa dentro da bibliografia sugerida pelos programas de mestrado na disciplina de Teoria da Contabilidade. A Tabela 6 demonstra como se deu esta incidência.

Tabela 6 - Livros citados nas bibliografias dos programas de mestrado

\begin{tabular}{|c|c|c|c|c|c|c|c|c|c|}
\hline \multirow{2}{*}{ Programa Mestrado - Bibliografias } & \multicolumn{9}{|c|}{ LIVROS } \\
\hline & 1 & 2 & 3 & 4 & 5 & 6 & 7 & 8 & 9 \\
\hline FUCAPE & $\mathrm{x}$ & $\mathrm{X}$ & & & & & $\bar{x}$ & & $\mathrm{x}$ \\
\hline FURB & $\mathrm{x}$ & $\mathrm{x}$ & & & $\mathrm{x}$ & & $\mathrm{x}$ & & $\mathrm{x}$ \\
\hline PUC/SP & $\mathrm{x}$ & $\mathrm{x}$ & & & & $\mathrm{x}$ & & & \\
\hline UERJ & $\mathrm{x}$ & $\mathrm{x}$ & $\mathrm{x}$ & & & & & & \\
\hline UFBA & $\mathrm{x}$ & $\mathrm{x}$ & $\mathrm{x}$ & & & $\mathrm{x}$ & & & $\mathrm{x}$ \\
\hline UFMG & $\mathrm{x}$ & $\mathrm{x}$ & & & $\mathrm{x}$ & $\mathrm{x}$ & $\mathrm{x}$ & & \\
\hline UFPE & $\mathrm{x}$ & $\mathrm{x}$ & & & $\mathrm{x}$ & $\mathrm{x}$ & $\mathrm{x}$ & & $\mathrm{x}$ \\
\hline UFPR & $\mathrm{x}$ & $\mathrm{x}$ & $\mathrm{x}$ & & & $\mathrm{x}$ & & & \\
\hline UFRJ & $\mathrm{x}$ & $\mathrm{x}$ & & & & & & & \\
\hline UFSC & $\mathrm{x}$ & $\mathrm{x}$ & $\mathrm{x}$ & & $\mathrm{x}$ & & & & \\
\hline UNB - UFPB - UFRN & $\mathrm{x}$ & $\mathrm{x}$ & & & & $\mathrm{x}$ & & & \\
\hline UniFECAP & $\mathrm{x}$ & $\mathrm{x}$ & $\mathrm{x}$ & & $\mathrm{x}$ & $\mathrm{x}$ & $\mathrm{x}$ & & $\mathrm{x}$ \\
\hline UNISINOS & $\mathrm{x}$ & $\mathrm{x}$ & & & & $\mathrm{x}$ & & & \\
\hline USP & $\mathrm{x}$ & $\mathrm{x}$ & & & & & & & \\
\hline USP/RP & $\mathrm{x}$ & $\mathrm{x}$ & & & & & $\mathrm{x}$ & & $\mathrm{x}$ \\
\hline
\end{tabular}

Fonte: elaborado pelos autores

Na seqüência, o Gráfico 1 demonstra os dados dispostos acima em termos percentuais. 


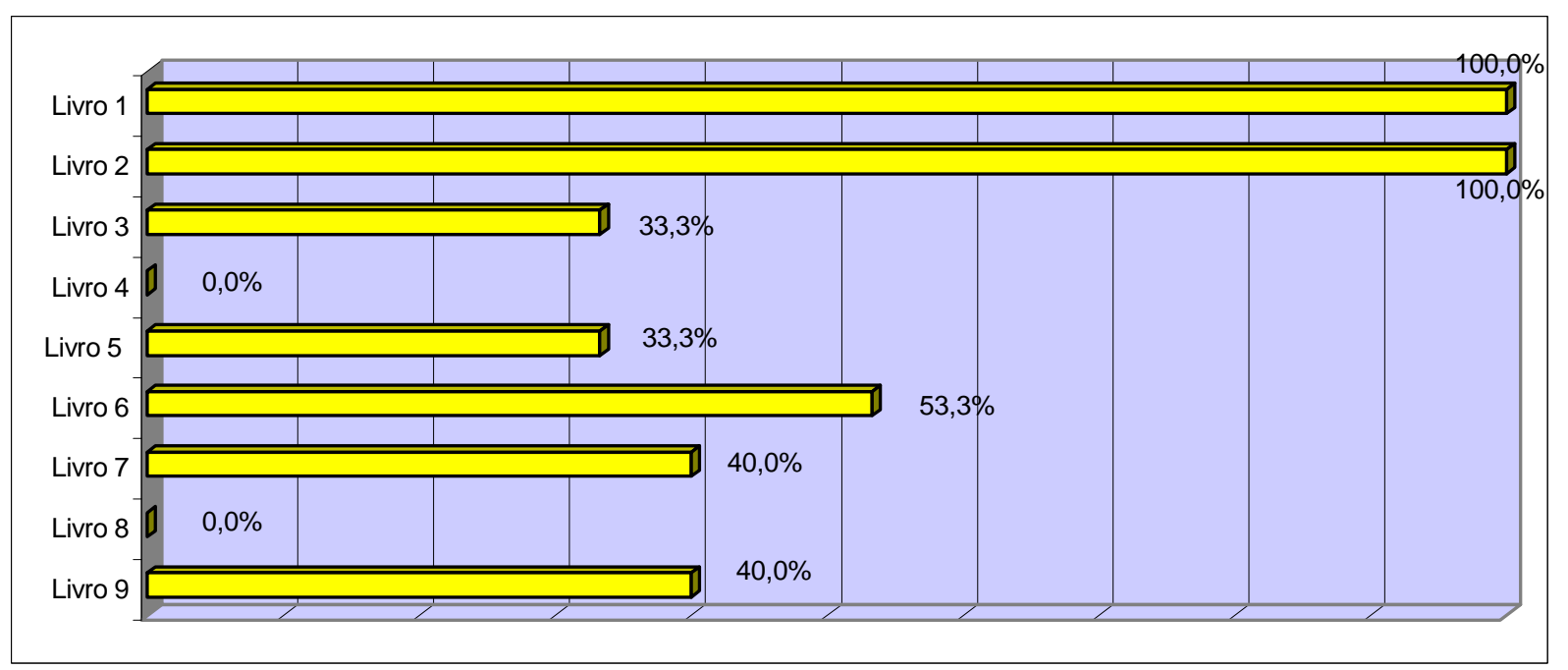

Gráfico 1 - Freqüência de citação dos livros

Dentre os livros-texto analisados, conforme visto anteriormente, as obras de Hendriksen e Van Breda são citadas em $100 \%$ das ementas, fato pelo qual serviram como base para esta pesquisa. No entanto, as obras de Evans e Sá não foram citadas em nenhuma das ementas. Nas demais obras, destaque para Kam, que consta em 53,3\% das ementas.

Quanto à busca pela disciplina Teoria da Contabilidade nos dez melhores programas de pós-graduação americanos, observou-se que apenas três oferecem disciplinas relacionadas de forma direta com Teoria da Contabilidade, quais sejam: University of Texas, University of Illinois e University of North Carolina. Abaixo, são apresentados os nomes das disciplinas pelos quais cada universidade abordou.

\section{- University of Texas: Studies in Accounting Theory}

- University of Illinois: Fundamentals of Accounting

- University of North Carolina: Accounting Theory

Dentre estas universidades, os temas abordados referem-se, de forma geral, a teoria da contabilidade financeira; pronunciamentos atuais sobre a teoria; pesquisa em contabilidade e princípios de contabilidade.

Cabe ressaltar que a pesquisa buscou verificar disciplinas relacionadas diretamente à teoria da contabilidade. Porém, podem existir outras disciplinas, com foco em outros temas, mas que abordem temas de teoria da contabilidade em seu conteúdo.

Observou-se, ainda, que nos programas americanos há grande enfoque para a contabilidade financeira voltada ao mercado de ações e, ainda, para a evidenciação e normatização contábil, sendo a maioria das disciplinas voltadas para estes temas.

\section{Conclusões}

O presente estudo teve como objetivo verificar as ementas e bibliografias da disciplina Teoria da Contabilidade ministrada nos programas de pós-graduação em contabilidade do Brasil, de modo a relacionar o conteúdo proposto nas ementas e a bibliografia sugerida, com livros de relevância sobre o tema.

Buscou-se, ainda, fazer um comparativo com os melhores programas de pósgraduação em contabilidade dos Estados Unidos, de modo a observar o oferecimento da disciplina teoria da contabilidade e verificar semelhanças ou diferenças com os programas de mestrado brasileiros. 
Dentre os livros pesquisados, verificou-se que todos os tópicos temáticos tiveram uma freqüência relativamente alta, com destaque para os Postulados, Princípios e Convenções que foram constatados em todos os livros analisados. Isto é visto positivamente, tendo em vista que os tópicos baseiam-se nos livros base e que estes são sugeridos por todos os programas de mestrado.

Verificou-se na análise do conteúdo das ementas que, novamente, os Postulados, Princípios e Convenções obtiveram a maior freqüência (93,3\%), enquanto que temas como Contabilidade e as Flutuações de Preços, Tópicos Especiais e Regulamentação Contábil obtiveram os menores índices.

Acredita-se que os Postulados, Princípios e Convenções obtiveram a maior frequiência, provavelmente, pela tamanha importância destes conceitos na construção da Teoria Contábil. Por outro lado, os temas com um grau inferior de abordagem, talvez reflitam uma ação mais conservadora dos docentes ao tratar de temas que estejam em constantes mudanças e que possam, em um futuro próximo, não mais refletir a realidade para os discentes que estudaram este conteúdo.

$\mathrm{Na}$ análise quanto à abordagem das ementas pelos programas de mestrado, verifica-se certo padrão na quantidade de temas previstos em suas ementas, sendo que dentre os 15 programas de mestrado, 10 possuem uma frequiência entre 63,6 e 72,7\%, ou seja, adotaram nas ementas entre sete e oito itens do total de 11 tópicos.

Os resultados quanto aos livros-texto analisados demonstram que as obras de Hendriksen e Van Breda são citadas em 100\% das ementas, fato pelo qual serviram como base para esta pesquisa. No entanto, as obras de Evans e Sá não foram citadas em nenhuma das ementas. Nas demais obras, destaque para Kam, que consta em 53,3\% das ementas.

É possível concluir com o estudo, que parece existir uma lógica no ensino da Teoria da Contabilidade pelos programas de mestrado. Diz-se isto pelo fato de que foi possível constatar no estudo que, de modo geral, os temas abordados por Hendriksen e Van Breda e por Iudícibus, tendem a refletir os temas abordados por diversos outros autores de teoria da contabilidade.

Posto isto, ainda verificou-se que as ementas também refletem a abordagem, em sua maioria, destes mesmos temas. Neste caso, pode-se dizer que os alunos destes programas de mestrado irão estudar os temas mais relevantes abordados pelos autores da área, o que é positivo no ensino de qualquer disciplina.

$\mathrm{Na}$ análise da disciplina teoria da contabilidade nos programas americanos, verificouse uma pequena oferta da disciplina, sendo que dos dez programas analisados, apenas três oferecem disciplinas mais específicas relativas à teoria da contabilidade.

Em todos os programas americanos, observou-se um forte enfoque na contabilidade financeira voltada ao mercado de ações e, ainda, evidenciação e normatização contábil, com oferecimento de diversas disciplinas que englobam estes temas.

Esta observação vem a refletir o grande potencial do mercado de ações e regulamentação americano, e pode servir de referência para que no Brasil, através das universidades de modo geral, possa se incentivar o interesse e o conhecimento por estes temas. Para que isso possa, no futuro, vir a se refletir no mercado de ações nacional, e na própria cultura brasileira de negociação e investimento acionário.

Para trabalhos futuros, poderiam ser estudadas outras disciplinas nestes mesmos programas de mestrado, ou a comparação do ensino em outros países. Poderiam ser utilizados, também, uma quantidade maior de obras ou a verificação da evolução do ensino ao longo do tempo. 


\section{Referências}

BELKAOUI, Ahmed Riahi. Accounting Theory. $3^{\text {a }}$ ed., Great Britain: University Press, Cambridge, 1993.

BEUREN, Ilse Maria. Como elaborar trabalhos monográficos em contabilidade. São Paulo: Atlas, 2003.

COORDENAÇÃO DE APERFEIÇOAMENTO DE PESSOAL DE NÍVEL SUPERIOR (CAPES). Disponível: http://www.capes.gov.br. Acesso em 10 out. 2010.

EVANS, Thomas G. Accounting Theory: contemporary accounting issues. United States: Thomson, 2003.

FRANCALANZA, Charles A. Accounting education and change in financial accounting. Journal of Accounting Education. Vol. 15, nº. 1, p. 109-122, 1997.

GALLON, Alessandra Vasconcelos. Disciplinas de custos: uma análise nos cursos de Ciências Contábeis das IES do sistema ACAFE. In: V Coloquio Internacional sobre Gestión Universitaria en América del Sur. Mar del Plata, dez., 2005.

GLAUTIER, M. W. E; UNDERDOWN, B. Accounting Theory and Practice. $5^{\text {a }}$ ed., London: Pitman Publishing, 1995.

HENDRIKSEN, Eldon S.; VAN BREDA, Michael F. Teoria da Contabilidade. $5^{\text {a }}$ ed., São Paulo: Atlas, 2009.

INANGA, Eno L.; SCHNEIDER, Wm Bruce. The failure of accounting research to improve accounting practice: a problem of theory and lack of communication. Critical Perspectives on Accounting. Vol. 16, p. 227-248, 2005.

IUDÍCIBUS, Sérgio de. Teoria da Contabilidade. $9^{a}$ ed., São Paulo: Atlas, 2009.

; MARTINS, Eliseu; CARVALHO, L. Nelson. Contabilidade: aspectos relevantes da epopéia de sua evolução. Revista Contabilidade e Finanças. Vol. 38, p. 7-19, mai/ago, 2005.

KAM, Vernon. Accounting Theory.2 $2^{\text {a }}$ ed., Canada: Wiley, 1990.

LAKATOS, Eva Maria. MARCONI, Marina de Andrade. Metodologia do trabalho científico. 4. ed. São Paulo: Atlas, 1992.

LOPES, Alexandre Silveira; et al. O Ensino de Contabilidade Estratégica nas IES Públicas do Estado do Rio de Janeiro. Sociedade, Contabilidade e Gestão, vol. 2, n. 2, 2007.

LOPES, Alexsandro B.; MARTINS, Eliseu. Teoria da Contabilidade: uma nova abordagem. São Paulo: Atlas, 2005.

LUEHLFING, Michael S. Methods of Consolidation in Current Accounting Textbooks. Journal of Accounting Education, Vol. 13, No. 3, pp. 349-365, 1995. 
LUZ, Rodrigo Marciano Da; RENGEL, Silene; DOMINGUES, Maria José Carvalho De Souza. Obras Didáticas Utilizadas no Ensino da Contabilidade: um estudo bibliométrico. In: XIII SEMEAD, set., 2010.

MARION, José Carlos. A disciplina teoria da contabilidade nos cursos de graduação algumas considerações. Contabilidade Vista \& Revista. Vol. 8, nº. 2, p. 3-8, 1997.

PINHEIRO, Fábio Araújo. O postulado do usuário: incentivo do desenvolvimento da teoria da contabilidade e do contabilista. Caderno de Estudos FIPECAFI. Vol. 9, nº. 6, p. 59-65, jul/dez, 1997.

RAUPP, Fabiano Maury. Metodologia da pesquisa aplicável às ciências sociais. In: BEUREN, Ilse Maria (Org.). Como elaborar trabalhos monográficos em contabilidade: teoria e prática. $2^{\mathrm{a}}$ ed. São Paulo: Atlas, 2004. p. 76-97.

RAUPP, Fabiano Maury; et al. O ensino de contabilidade de custos nos cursos de graduação em administração do Estado de Santa Catarina. Associação Brasileira de Custos. Vol. IV, no 2, mai-ago, 2009.

SOUZA, Antônio Artur de; et al. Ensino da Contabilidade Gerencial: Estudo dos Cursos de Ciências Contábeis das Melhores Universidades Brasileiras. Revista Contemporânea de Contabilidade. Vol. 1, nº.10, p. 69-90, Jul./Dez., 2008.

SULLIVAN, M. Cathy; BENKE JR.,Ralph L. Comparing Introductory Financial Accounting Textbooks. Journal of Accounting Education, Vol. 15, No. 2, pp. 181 220, 1997.

U.S. NEWS \& WORLD REPORT. Disponível: http://www.usnews.com/ Acesso em: 01 mar. 2011. 